best known for his work on the theory of generalized hypergeometric series; much of this was incorporated in his Cambridge 'tract' on this subject, an excellent booklet which makes pleasant reading. To him are due two new methods of obtaining transformations of such series; one is algebraic and the other uses contour integrals of Barnes' type. These methods led to various generalizations in the theory, and applications were made to Bessel functions and Legendre functions. Some of his most important work in this field concerned infinite integrals in which the integrand involved the product of three Bessel functions. The argument used an earlier result of his, that Appells' hypergeometric function of two variables could in a particular case be expressed as a product of two ordinary hypergeometric functions. This case has since been of use to other writers and has led to new researches. His most recent work, which is in process of publication, is on the problem of finding transformations of hypergeometric series of both the ordinary and the basic type. Previously, no general method of obtaining transformations of basic series had been given. His new point of view has led to new transformations of basic series, thrown further light upon them and has also led to numerous identities of the Rogers-Ramanujan type.

\section{Science and Industry at Manchester}

The Manchester Chamber of Commerce has done well to issue in pamphlet form ( $\mathrm{Pp} .63 .18 .6 d$.) the addresses given at the four meetings on "Science and Industry" in March and April last. The pamphlet contains not only the addresses of Lord Riverdale, Dr. A. P. M. Fleming, Dr. Andrew McCance and Sir Edward Appleton, which have already been noted in these columns, but also other addresses given at the meetings, such as those of Sir Raymond Streat, Mr. A. H. S. Hincheliffe, announcing the formation of a Joint Standing Council of the Chamber and of the University of Manchester, Mr. C. C. Renold and Mr. R. H. Dobson. Mr. C. C. Renold, following Dr. Fleming's address on 'Research Workers: their Education and their Place in Industry", referred particularly to the traditional industries where the application of science should involve challenging the traditions themselves, not merely tuning them up or their further evolution. The emphasis should be on the application of what is already known rather than the extension of the boundaries of knowledge, and $\mathrm{Mr}$. Renold suggested that for the medium-sized traditional concern the key move is the appointment of a scientific liaison officer with broad and general rather than specialized scientific qualifications. His job should be to recognize the problems and indicate lines worthy of investigation, and to help the practical men to apply the answers. With this fairly highranking appointment in the management, a re-casting of management structure might also be necessary to separate those functions of management which lend themselves to contact with the scientific liaison officer and thereby provide a convenient channel for his influence to become effective. Some re-casting of the accepted curricula of teaching may be required to provide men of the necessary breadth of scientific appreciation. Mr. R. H. Dobson, following Dr. McCance's paper on the application of research, referred to the bearing of fundamental research on the export trade of Britain, and to the necessity of creating a liaison and a free interchange of ideas and work between technical assistants and the people on the shop floors.

\section{Looting of Simeis Observatory}

A TELEGRAM received at the Royal Observatory, Greenwich, from G. A. Shajn, member of the Academy of Sciences of the U.S.S.R., gives an account of the fate suffered at the hands of the enemy by the Simeis Observatory in the Crimea. A week or two before the Germans occupied the southern part of the Crimea, the staff of the Observatory was evacuated, the workers taking with them the object glasses of the two astrographs and part of the laboratory equipment. In May 1944, after the Crimea had been liberated by the Red Army, the Academy of Sciences sent Dr. Shajn to inspect the remains of the Observatory. He established the following facts. During September and October 1943 German specialists dismantled all the Observatory's instruments and moved them in thirty or more trucks to Simferopol, whence they were dispatched to Germany. The equipment stolen was the 40 -in. reflecting telescope, the double astrograph, a new astrograph for zonal observations, a photoheliograph, three stellar spectrographs, a large cœlostat, a long-screw measuring machine, a Repsold machine, a microphotometer and two astronomical clocks.

In addition to this, much other laboratory equipment and the whole library collection of more than nine thousand negatives, and the equipment of the power station and workshop were all taken away. The wooden parts of three observatory domes were destroyed, and one of them was used as a stable. The wooden building which housed the spectrohelioscope was also destroyed, as were a number of other pavilions. On January 18, 1944, the main building of the Observatory, where a Rumanian army unit was quartered, caught fire. It continued to burn for two days, but the cormmander of the unit did not call out the fire brigade nor did he take any steps to extinguish the flames. British men of science will sympathize with Russian astronomers in the looting and wanton destruction of this famous Observatory.

\section{Tropical Diseases Investigation in New York}

A RECENT article in Nature (May 9, 1944, p. 625) referred to the part played by parasitic diseases in war and to the realization by American physicians that these diseases constitute a grave danger to their troops overseas. Prof. H. W. Stunkard (Ann. New York Acad. Sci., 44, Art. 3, 189; 1943) has referred to the absence of adequate instruction in tropical medicine or of any institution devoted primarily to work on parasitic diseases in the United States. Nuttall, Brumpt and Fülleborn, he states, thought that New York should provide the financial support for such an institution, because it is the principal shipping and commercial centre in the United States. In time of war, Prof. Stunkard points out, it is one of the chief ports of embarkation and disembarkation, so that there is acute need there for diagnostic, therapeutic and research work. The Columbia University Department of Public Information now announces that plans are being formulated which will, if they are carried out, make New York City a world centre of teaching and research in tropical medicine. Dr. H. S. Mustard, director of the DeLamar Institute of Public Health, Columbia University School of Medicine, states that a substantial beginning has been made, thanks to a temporary grant from the Macy Foundation. An additional grant from the John and Mary H. Markle 